\title{
Formalization and Consistency Heighten Organizational Rule Following: Experimental and Survey Evidence
}

\author{
Published in Public Administration (2018): \\ https://onlinelibrary.wiley.com/doi/full/10.1111/padm.12407
}

\begin{abstract}
This study examines the attributes of organizational rules that influence rule following. Rule following fosters organizational effectiveness by aligning individual behaviors with organizational preference. While a range of theoretical explanations has been offered for rule following, the characteristics of rule design and implementation have received less empirical attention. Borrowing from the green tape theory of effective rules, this study examines the influence of two particular characteristics — rule formalization and rule consistency —on rule following. Three studies, which include two vignette experiments and a survey of two local government organizations, provide the data for the research. The results suggest that rule formalization and rule consistency independently increase rule following, with mixed evidence of interaction effects. The broad implication is that public managers must attend to both rule design and implementation to foster organizational rule following.
\end{abstract}

\section{Authors}

Erin L. Borry, ${ }^{*}$ Department of Political Science and Public Administration, University of Alabama at Birmingham, Birmingham, Alabama, USA, http://orcid.org/0000-0001-5346$\underline{2426}$

Leisha DeHart-Davis, School of Government, University of North Carolina-Chapel Hill, Chapel Hill, North Carolina, USA, http://orcid.org/0000-0001-9406-3851

Wesley Kaufmann, Tilburg Institute of Governance, Tilburg University, Tilburg, Noord-Brabant, The Netherlands

Cullen C. Merritt, School of Public and Environmental Affairs, Indiana University-Purdue University Indianapolis, Indianapolis, Indiana, USA

Zachary Mohr, Department of Political Science \& Public Administration, University of North Carolina at Charlotte, Charlotte, North Carolina, USA

Lars Tummers, Utrecht University School of Governance, University of Utrecht, Utrecht, The Netherlands, http://orcid.org/0000-0001-9940-9874

*Corresponding Author:

Erin L. Borry, Department of Political Science and Public Administration, University of Alabama at Birmingham 409 Heritage Hall, $17202^{\text {nd }}$ Ave S, Birmingham, Alabama

35294-1152, USA

borry@uab.edu 


\section{Introduction}

Rule following is a fundamental work task for public employees. Organizational rule following shapes the pursuit of the public interest and the effectiveness of bureaucratic structure (Wise, 2004). It signifies the legitimacy of authority (DeHart- Davis, Chen, \& Little, 2013), the effectiveness of group functioning (Tyler \& Blader, 2001), and the strength of public sector accountability (Romzek \& Dubnick, 1987). Rule following also implies the effectiveness with which public values such as equity, transparency, and accountability are delivered (Bozeman, 2000) and enables a host of organizational functions that cannot be achieved otherwise, including coordination (March \& Simon, 1958; Stinchcombe, 2000), legitimacy (Weber, 1947; Rubin, 2009; Sitkin \& Bies, 1993), socialization (Vlaar, Van den Bosch, \& Volberda, 2006; Ocasio, 1997; Olsen, 2006) and knowledge storage and transfer (March, Shulz, \& Zhou, 2000).

While this paper construes rule-following as organizationally beneficial, such a conclusion assumes that organizational rules are always used to pursue social good through rational means. This assumption is not always warranted: consider the use of rules in Nazi German (Osiel 2001) and by United Nations staffers who passively observed the Rwandan genocide (Barnett 2002). At the mundane level of organizational functioning, rule following cannot be organizationally beneficial if rules are illegitimate, burdensome, or illogical (Bozeman and Feeney 2011). Rule following can be organizationally and societally beneficial, but this is not always the case. Nonetheless, many public sector rules are functional, making rule following a critical function within public organizations that is worthy of study (DeHart-Davis 2019).

So why do public employees follow or break organizational rules? Scholars offer a range of theoretical explanations, some pertaining to organizational factors, such as performance pressures (Sandfort, 2000; Sekerka \& Zolin, 2007; Tummers et al., 2015) or organizational 
culture (Pandey \& Moynihan, 2006; Borry, 2017), while others focus on individual influences such as personality (Bozeman \& Rainey, 1998; DeHart-Davis, 2007) or professional or gender socialization (Portillo \& DeHart-Davis, 2009; Kaufman, 1960; Hutchinson, 1990). Still others draw on interactions of the individual with the organization: perceived risks and benefits (Battmann \& Klumb, 1993), extrinsic vs. instrinsic mechanisms (Tyler \& Blader, 2005), or the relationships between public employees and citizens (Maynard-Moody \& Musheno, 2003; Riccucci 2004; Henderson 2013).

One set of factors in rule following that has received less scholarly attention include the attributes of organizational rules themselves. The study of rule attributes is a relatively new emphasis that departs from the notion of rules as monolithic forms of structure, as conceptualized by early organizational scholars (Pugh, Hickson, Hinings, \& Turner, 1968). Distinctive attributes distinguish organizational rules from one another, both during rule design and implementation processes. To illustrate, rules can be enabling or coercive depending on the content of the rule, the rule development process, and the circumstances under which they are applied (Adler \& Borys, 1996). Rules can be more or less well-understood, controlling or logically designed (DeHart-Davis, 2009a), or democratically derived (Tummers, 2012). A focus on rule attributes and their role in rule following not only strengthens theoretical understanding of the functioning of organizational rules, but also offers practical implications that can be acted upon by public administrators in the pursuit of organizational effectiveness.

This study examines two attributes of organizational rules, rule formalization and consistency, with particular potential to influence rule following. Both attributes are theoretical dimensions of 'green tape', or effective organizational rules (DeHart-Davis, 2009a). Rule formalization, the extent to which rules are written, is expected to increase rule following by 
focusing the attention of organizational members on rule requirements and conveying their legitimacy (DeHart-Davis, et al., 2013). The consistency of rule application is expected to increase rule following by conveying to rule followers 'peripheral cues', the support of 'like others' for rule requirements (Brehm \& Gates, 1997). Combining the anticipated effects of legitimacy, attention focusing, and peripheral cues, rule formalization and consistency are also expected to interact to produce a higher level of rule following than is achieved by either rule attribute alone.

To investigate these links, this study uses multiple methods of investigation — two vignette experiments and an organizational survey of two local government organizations - to examine the influence of rule formalization and consistency on rule following. This research answers the call for more multi-method research in public administration and specifically more emphasis on using experiments (Perry, 2012).

This paper begins by mapping out the theoretical relationships between rule formalization, consistency and rule following. The next section details the research design and results of the three studies. The final sections identify limitations, discuss the theoretical and practical significance of the results, and draw conclusions about the paper's contributions.

\section{Theory and Hypotheses}

While both individual and organizational factors influence rule following (DeHart-Davis 2017), this article examines one type of organizational influence: the characteristics of rules themselves. The conceptual foundation for making this argument is green tape theory, which argues that specific attributes of organizational rules alter the probability that a rule will be effective (DeHart-Davis, 2009a). Specifically, green tape theory posits that effective rules require technical capacity and stakeholder cooperation, i.e., effectively designed rules that 
people are willing to follow. From this perspective, rule effectiveness is a function of rule design and rule following (DeHart-Davis, et al., 2013). Five rule attributes — rule formalization, rule logic, rule consistency, optimal control, and understood rule purposesare expected to strengthen rule design and increase rule rule following.

Our inquiry represents a partial test of green tape theory, focusing on effects of two organizational rule attributes that are particularly relevant for our understanding of rule following: rule formalization and rule consistency. Rule formalization pertains to the extent to which organizational rules are written, while rule consistency is defined as the reliability with which rules are applied to individuals and groups. The formalization and consistency of organizational rules are defining features of bureaucratic structure, signaling both form (Stinchcombe, 2001) and function (Weber, 1947). We begin by hypothesizing the effects of rule formalization on rule following.

\subsection{Rule Formalization and Rule Following}

Rule formalization describes the written quality of rules (DeHart-Davis, Mohr, \& Davis, 2014). While organizational formalization describes the extent of written policies, procedures, and regulations (Pugh et al., 1968), rule formalization pertains to the process and outcome of putting policies, procedures, and regulations in writing (DeHart-Davis, et al., 2013). Rules vary in formalization on a continuum from completely written to completely unwritten (Pugh et al. 1968; Kieser, Beck, \& Tainio 2001; March, Schulz, \& Zhou 2000).2 An unwritten rule is still a rule, defined here as 'requirements for specific organization behaviors under particular circumstances' (DeHart-Davis, Chen, \& Little 2013, p. 333), but is disseminated verbally and stored in memory. Examples of unwritten rules referenced in the literature include those governing overtime pay 
(DeHart-Davis 2009b), allowable e-mail communications (Gilsdorf 1987; 1998), and promotion processes (Roth \& Sonnert, 2011).

Rule formalization is expected to increase rule following via two related but distinct processes that derive power from the written word: attention focusing and legitimacy. Organizational attention is the 'distinct focus of time and effort by the firm on a particular set of issues, problems, opportunities, and threats...' (Ocasio 1997, p. 188). Rule formalization is one means of focusing attention (Stinchcombe, 2000), enabling the organization to narrow the information flow that pervades individual consciousness to specific issues of concern to the organization. While both written and unwritten rules can focus the attention of organizational members (Schulz, 2003), the inscribed nature of written rules expedites the process by providing visible evidence of preferred organizational behaviors that is more accessible, recognizable and easily disseminated than the spoken delivery of unwritten rules (Levitt \& March, 1988; Sutcliffe \& McNamara, 2001).

Legitimacy is the second mechanism by which rule formalization is expected to influence rule following. Legitimacy is the perception of authority as 'appropriate, proper, and just' (Tyler, 2006, p. 375). Legitimacy is furthered by a sense of neutrality and fairness (Tyler \& Lind, 1992; Blader \& Tyler, 2003), which engender a sense of obligation to cooperate and greatly increasing the likelihood of rule following (Tyler \& Blader, 2005). Rules are one source of legitimate authority to public employees (DeHart-Davis, 2017) which, as other sources of authority, can be obeyed or disobeyed. By contrast, perceptions of legitimacy are more difficult to achieve through unwritten rules (DeHart-Davis, 2009a), which are communicated through speech, inherently attached to specific people and situations, and indicative of power relationships created by personal sources of authority (Gouldner, 1954). As a result, unwritten rules are more likely to 
raise the specter of arbitrary and capricious power, failing to provide evidence of the neutrality and fairness that feed legitimacy perceptions and ultimately rule following (Tyler, 2006; Tyler \& Blader, 2005; Levi, Sacks \& Tyler, 2009).

The capacity of rule formalization to focus attention and convey legitimacy leads us to hypothesize that:

$H_{1}$ : Written rules will be followed at higher rates than unwritten rules.

\subsection{Rule Consistency and Rule Following}

Consistency of administrative action towards both internal and external stakeholders is integral to effective public organizations. Consistent administrative behavior renders organizational action predictable and coordinated in the pursuit of organizational goals (Weber, 1947; Hummel, 2007). In the context of green tape, consistent application is expected to elicit stakeholder cooperation with rule requirements and ensure organization-wide implementation of managerial preferences (DeHart-Davis, 2009a). Beyond green tape, consistency has been associated with quality federal regulation (Bertelli \& Whitford, 2009), optimal policy planning (Kydland \& Prescott, 1977), and procedural justice perceptions among key stakeholders (Leventhal, 1980). In each of these studies, rule consistency is viewed either as an outcome or mechanism for other positive outcomes of formal organizational structure.

Rule consistency is expected to increase rule following by sending signals that support rule following from the perspective of 'like others'. Brehm and Gates first made this argument in their study of street-level bureaucratic behavior (1997). Drawing on related strands of social science research, the authors argued that individual organizational members interpret signals 
from the workplace environment to understand behavioral norms (Salancik \& Pfeffer, 1978). When it is unclear which behavioral options are most desirable, organizational members will look to peer behavior to lower the uncertainty of their options (from Festinger, 1954). Drawing on Cialdini's research on persuasion (1984), Brehm and Gates argue that signals can be 'central,' which stem from direct influences such as supervisory direction and the consequences of rule violations, or 'peripheral', which require a consideration of what one has done in the past and what like others are doing. To illustrate, Brehm and Gates find that police officers who have more contact with both fellow officers and supervisors during a shift have higher rates of shirking, measured by independent observers as 'goofing off' or conducting personal business at work. The authors' survey of social workers produced mixed results regarding peripheral cues: influential co-worker relationships increased the likelihood that paperwork would be taken home and rules bent, but had no effect on whether paperwork was 'fudged' (1997, pp. 120-6).

Applying the concepts of peripheral cues, the extent of rule consistency is expected to signal managers about the acceptability of rule bending in the organization and, consequently, alter the likelihood that they are willing to bend the rules themselves. Accordingly, we hypothesize that:

$\mathrm{H}_{2}$ : Consistently applied rules will be followed at higher rates than inconsistently applied rules.

\subsection{Rule Formalization, Consistency and Rule Following}

Rule formalization and consistency are also expected to interact to increase rule following beyond that achievable by either organizational rule attribute alone. This interaction effect is expected based on the assumption that written organizational rules, because they more 
explicitly convey the legitimacy of preferences for organizational behavior than unwritten rules, will lower the likelihood of inconsistent application across individuals and groups within organizations (Kieser, Beck, \& Tainio, 2001). By contrast, rules that are not formalized and therefore unwritten leave more room for interpretation and greater opportunity for systematic deviation, by definition (McPhee, 2004). Put differently, the written nature of rules makes it more suitable for consistent application as opposed to unwritten rules. The hypothetical interaction between rule formalization and consistency follows the logic of organizational rationality, which employs structure as a means of making behavior more predictable and effective for achieving organizational objectives (Hasselbladh \& Kallinikos, 2000; Kallinikos, 1996). Accordingly we hypothesize that:

$H_{3}:$ Rule formalization and consistency will interact to induce higher rates of rule following than rule formalization or rule consistency alone.

\section{Research Design}

Three study designs are used to test the relationship between rule formalization, consistency and rule following: two vignette experiments and a survey of the employees of two local government organizations. An advantage of employing both experiments and surveys is that each offsets the strengths and weaknesses of the other. Experiments randomize research participants into treatment and control groups, thus minimizing the likelihood of systematic differences between groups. Furthermore, experimental designs enable the research to identify cause and effect relationships. Experiments have high internal validity by imposing identical conditions on all research participants. Surveys are lower in internal validity, but have the 
strength of external validity as responses are based on observations of the lived experiences of research participants, given sufficient sample sizes.

In terms of sample selection, our aim was to select research subjects that both match our study designs and have been used previously in the field. For the first, single-factor vignette experiment, we used an MPA student sample. Using a student sample in the context of a vignette study is in line with the approach taken by, among others, Kaufmann and Feeney (2014), Tummers et al. (2016) and Moynihan (2013). While the random assignment of participants ensures that meaningful conclusions can be drawn from a student sample, student samples have also been challenged as being insufficiently representative of 'real' employees. For this reason, our second experiment, which has two factors (one of which is identical to the single factor from the first experiment), was administered to a group of public managers. Finally, our survey sample consists of a diverse representation of employees at two public organizations, adding to the generalizability of our findings. While ideally our experimental studies could have been repeated using different samples and more organizations could have been included in our survey study, we believe that our overall approach has enabled us to triangulate on settings (e.g. Scandura \& Williams 2000). Below, we outline the specifics of the vignette experiments (Studies 1 and 2) and the survey (Study 3).

\subsection{Study 1: Single-Factor Experiment}

The first study involves a single-factor vignette experiment with formalization of the rule as the manipulated variable and rule following as the outcome of interest. The research subjects were 75 Masters of Public Administration (MPA) students enrolled in two organizational analysis and two public finance courses at a large university in the Midwestern United States. 
The experiment was designed to test the first hypothesis about the effect of rule formalization on rule following.

The experiment was administered at the end of class. Students were not compensated and participation was voluntary. The organizational analysis class received two points of extra credit on an upcoming exam. Research participants were randomly assigned into one of two experimental conditions. Both conditions involved a workplace scenario where the respondent was asked to take on the role of a supervisor and decide whether to follow or break a rule that would require suspending an employee for a week because of too many unexcused absences. One participant failed to indicate whether they would follow the rule or not. Therefore, the final number of participants was 74 . Figure 1 details the experimental conditions.

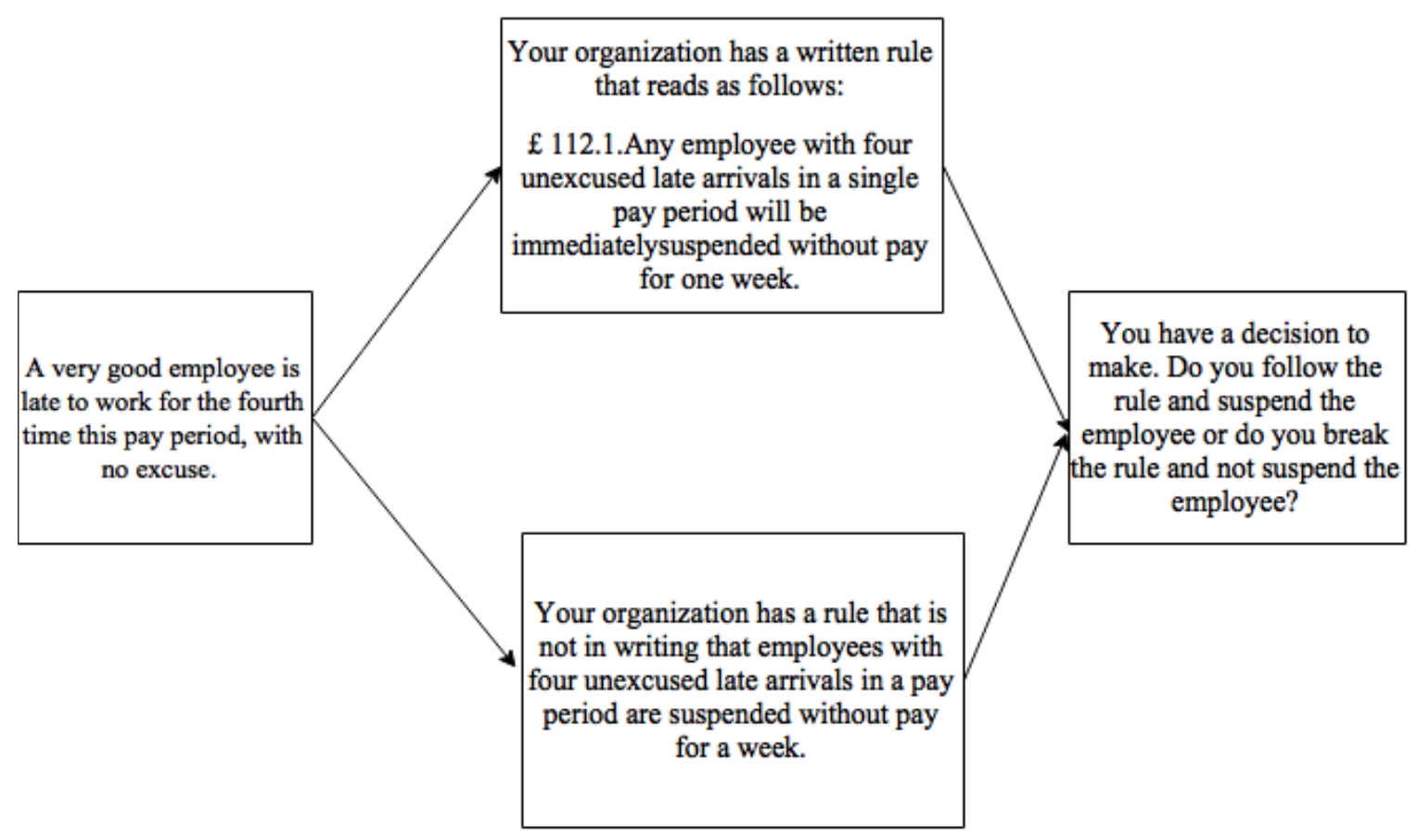

\section{Figure 1.}

Experimental Study 1 Conditions

Rule following was measured as a dichotomous choice between breaking a rule and following a rule. While there are many types of rule behavior (e.g., prosocial rule breaking 
(Morrison, 2006), rule rigidity (Merton, 1940), discretionary rule behavior (Maynard-Moody \& Portillo, 2010), the simplified notion of rule following as either rule bending or rule following is a common one that allows us to test the relative strength of the written versus unwritten nature of rules on rule behavior. Thus, the end of the vignette asked research participants to choose whether to 'follow the rule' by suspending the employee or 'break the rule' by not suspending the employee. The order of rule following versus rule breaking (whether presented first or second) was rotated to eliminate the risk of bias toward the first choice and minimize social cueing to either follow or break the rule. The vignette was followed by a brief survey that included a manipulation check and demographic questions.

The vignettes were randomly assigned by alternately distributing the written and unwritten rule scenarios to students. A cover sheet was placed over each packet so that research participants could not see the vignette assigned to their neighbor. To check that random assignment produced comparable conditions, the groups were compared for age, gender, work experience in the public sector, and previous and current management experience.

Table 1: Sample Composition on Study 1 Background Variables

\begin{tabular}{llllll}
\hline & $\begin{array}{l}\text { Average } \\
\text { Age } \\
\text { (Years) }\end{array}$ & Female & $\begin{array}{l}\text { Work in } \\
\text { Public } \\
\text { Sector }\end{array}$ & $\begin{array}{l}\text { Prior } \\
\text { Mgmt } \\
\text { Experience }\end{array}$ & $\begin{array}{l}\text { Current } \\
\text { Mgmt } \\
\text { Experience }\end{array}$ \\
\hline Unwritten & 29.62 & $42 \%$ & $63 \%$ & $19 \%$ & $31 \%$ \\
Written & 29.41 & $56 \%$ & $77 \%$ & $15 \%$ & $26 \%$ \\
Mean & 29.51 & $49 \%$ & $70 \%$ & $17 \%$ & $29 \%$ \\
$\begin{array}{l}\text { Difference } \\
\text { Tests }\end{array}$ & $\mathrm{t}=0.102$ & $\chi^{2}=1.628$ & $\begin{array}{l}\chi^{2}=1.701 \\
\mathrm{p}=.192\end{array}$ & $\begin{array}{l}\chi^{2}=0.215 \\
\mathrm{p}=.643\end{array}$ & $\begin{array}{l}\chi^{2}=0.224 \\
\mathrm{p}=.636\end{array}$ \\
\hline
\end{tabular}


Experimental participants vary in demographic and professional characteristics (Table 1). The average research participant was 29.5 years of age and women comprised 49.3 per cent of study participants. Seventy per cent of the participants were working in the public sector, 17.3 per cent had previous management experience, and 29.3 per cent had current management experience. Independent samples t-tests and chi-squared tests show that the groups are comparable in demographic and experience characteristics. This cancels out potential confounding effects, making it unnecessary to include these background variables in the analyses for the experiment (Campbell, 1963).

The experiment revealed that rule following is strongly influenced by whether the rule is written (Figure 1). Sixty-eight per cent of experimental participants receiving the written rule condition indicated that they would comply, compared with only 36 per cent receiving the unwritten rule. Thus, having written rules nearly doubles rule following. Proportional difference tests between the written and unwritten scenarios are statistically significant $(\mathrm{z}=2.78, \mathrm{p}<.01)$. This result confirms the first hypothesis, that rule formalization elicits more rule following than unwritten rules. 


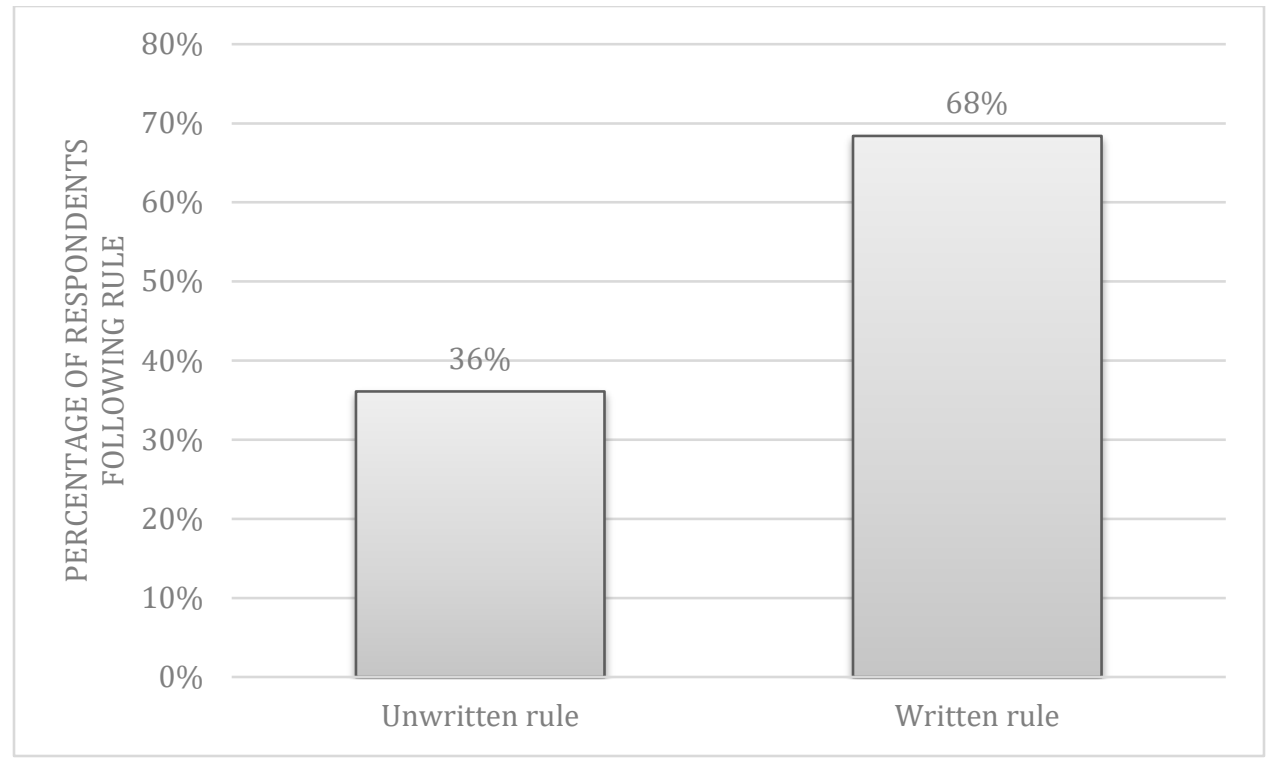

Figure 2. Rule Formalization and Rule Following

\subsection{Study 2: Two-Factor Experiment}

The second study is a $2 \times 2$ between-subject experiment with rule formalization and consistency as the manipulated variables. The research subjects were 150 public works managers in the Southeastern United States. The average age was 49 years $(\mathrm{SD}=8.20)$ and 46 per cent of the public works managers in our study were female. The experiment was administered online using Qualtrics, an online survey platform. Participants were recruited through a public works association and rewarded with free admission to a webinar on human resource management. Research participation was voluntary and anonymous, with no identifiers collected.

Research participants were assigned into one of four experimental conditions (Figure 3), featuring an organizational rule that was either (1) written and consistent, (2) unwritten and consistent, (3) written and inconsistent, and (4) unwritten and inconsistent. The organizational rule is the same that was used in Study 1, with the requirement to suspend without pay any 
employee with four unexcused late arrivals in a pay period. Figure 3 depicts the experimental conditions.

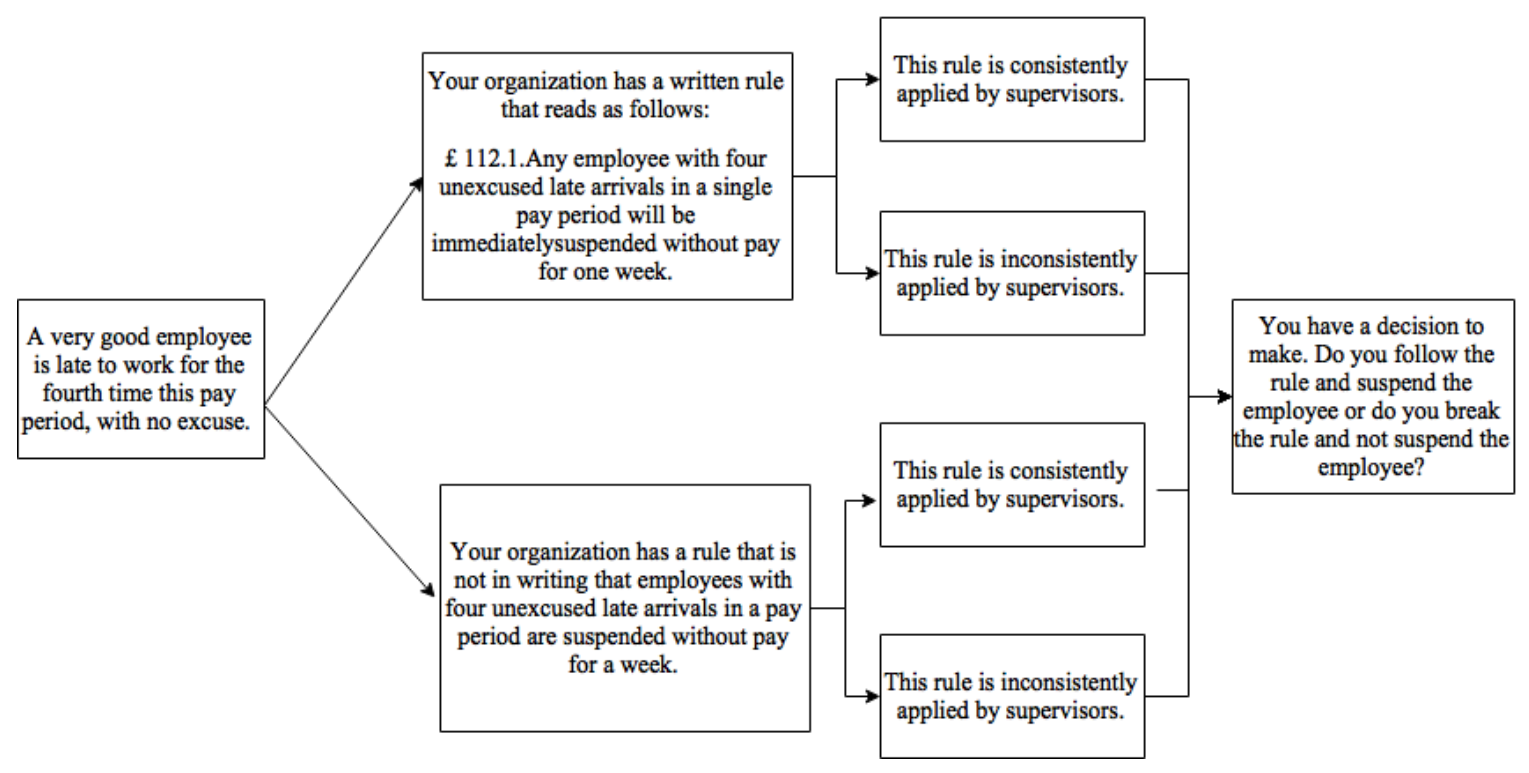

Figure 3. Study 2 Experimental Conditions

Table 2 compares the demographic variables that could affect rule following, such as age and gender, between the four groups. The differences between the control and treatment groups on gender and age are all insignificant, indicating that the groups were equivalent with regards to these variables. This cancels out potential confounding effects, making it unnecessary to include these background variables in the analyses for the experiment (Campbell, 1963). 
Table 2. Sample Composition on Study 2 Background Variables

\begin{tabular}{|c|c|c|}
\hline & $\%$ Female & $\begin{array}{l}\text { Average } \\
\text { Age }\end{array}$ \\
\hline Unwritten, Inconsistent & $47 \%$ & 49.71 \\
\hline Unwritten, Consistent & $58 \%$ & 49.95 \\
\hline Written, Inconsistent & $47 \%$ & 47.37 \\
\hline Written, Consistent & $31 \%$ & 47.88 \\
\hline Mean & $46 \%$ & 48.73 \\
\hline Difference Tests & $\begin{array}{l}\text { Chi Square }=5.679 \\
p=.128\end{array}$ & $\begin{array}{l}\text { ANOVA, } \\
\mathrm{F}=.925, \\
\mathrm{p}=.431\end{array}$ \\
\hline
\end{tabular}

Proportional difference testing revealed a significant main effect of written rules on rule following: 50 per cent of the participants that received the unwritten version of the rule said that they would follow the rule in this scenario. Conversely, a high number (89.2 per cent) of the participants that received the written rule said that they would follow the rule in this scenario. Proportional difference tests between the written and unwritten scenarios are highly statistically significant $(\mathrm{z}=5.20, \mathrm{p}<.01)$. Hence, results further confirm the first hypothesis that written rules elicit greater rule following than unwritten rules.

Proportional difference testing also revealed a significant main effect for rule consistency on rule following $(\mathrm{z}=3.19, \mathrm{p}<.01)$. Eighty-one per cent of experimental participants receiving the consistently applied rule complied with it, compared to 57 per cent receiving the inconsistently applied rule. This difference of nearly 24 per cent confirms the second hypothesis that consistently applied rules will elicit higher rule following than inconsistently applied rules.

As Figure 4 indicates, the rule that is both written and consistently applied increases the percentage of respondents that follow the rule, but not enough to support a statistically significant interaction effect anticipated by the third hypothesis. The written and consistent 
condition elicits higher rule following than the unwritten and consistent condition ( $\mathrm{z}=3.50$, $\mathrm{p}<0.01)$, the written and inconsistent condition $(\mathrm{z}=2.25, \mathrm{p}<0.05)$ and the unwritten and inconsistent condition $(\mathrm{z}=5.98, \mathrm{p}<.001)$. Practically, the effect sizes are large. In the unwritten and inconsistent condition, only 34 per cent of the managers followed the organizational rule. Rule following increased to 66 per cent for the unwritten and consistent condition and to 81 per cent for the written and inconsistent condition. When research participants received a rule that was both written and consistently applied, 97 per cent said that they would comply. This is a difference of 31 per cent for consistently applied rules that differed only in whether they were written or unwritten, and a difference of 16 per cent in written rules that are consistently versus inconsistently applied.

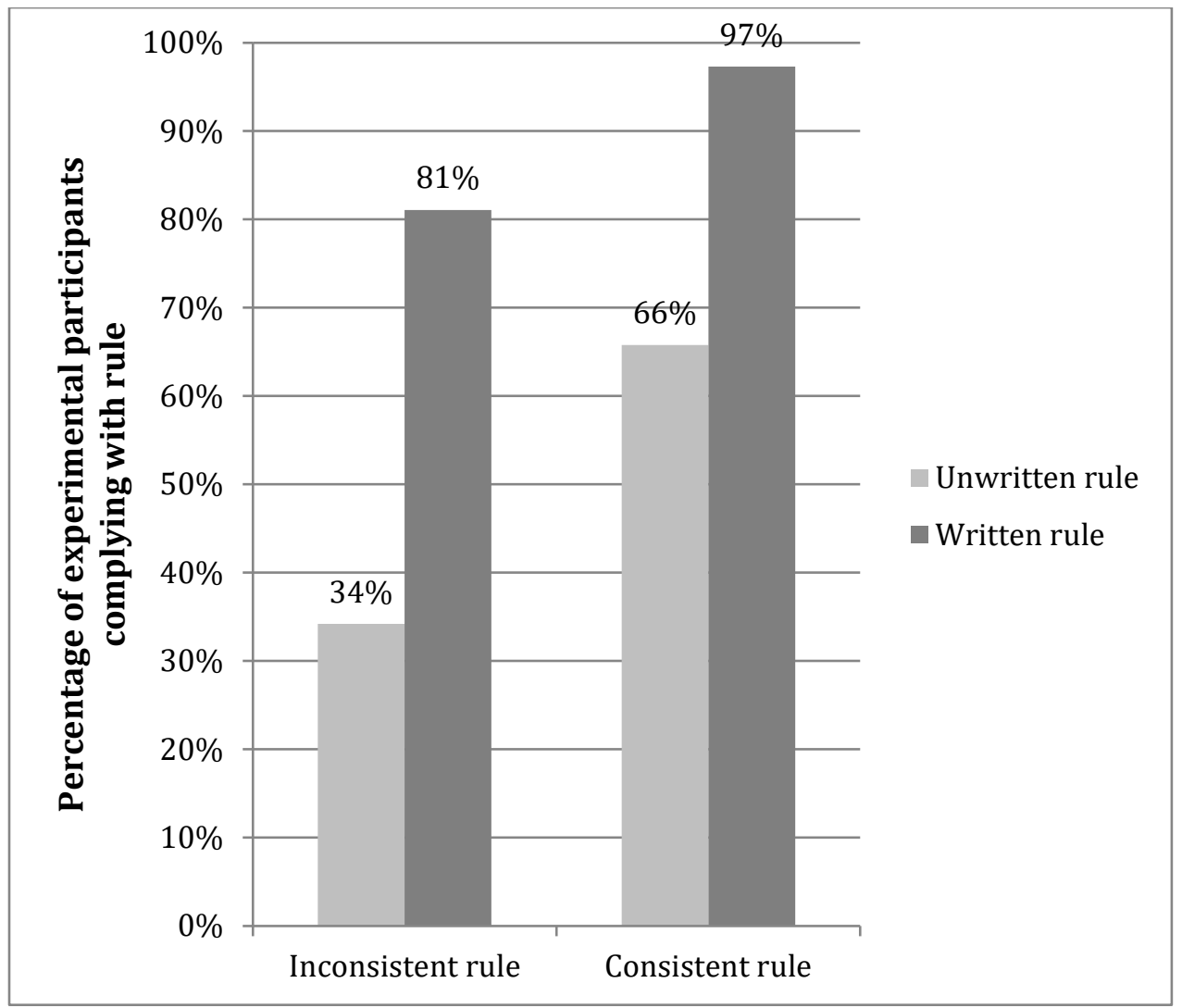

Figure 4. Rule Formalization, Consistency and Rule following 


\subsection{Study 3: Organizational Survey}

The third study collected survey data from the employees of two local government organizations, a medium-sized college town and a consolidated city-county mental health department in a state of the Southeastern U.S. The two organizations were participants in the Local Government Workplaces Project, a cross-organizational data collection started in 2004 to study organizational dynamics in cities and counties.

The research team sought the perspectives of employees throughout each organization's hierarchy, representing an 'echelon' approach of multiple informants with different organizational perspectives (Walker \& Brewer, 2008). As such, questionnaires were distributed to all members of both organizations, totaling 1,027 employees. Communications between researchers and respondents were structured based on the tailored design method for mixedmode surveys, featuring multiple contacts and consistent messaging with prospective research participants (Dillman, Smyth, \& Christian, 2009). Each survey process began with an alert letter from the top organizational leader expressing support for the study, encouraging voluntary participation and guaranteeing confidentiality. Within two weeks of the alert letter, surveys were distributed through Qualtrics. In the case of the town, paper questionnaires were also distributed to employees without regular email access and who preferred to complete paper surveys. Mental health department employees were surveyed only using Qualtrics. Whether collected through paper or Internet, all survey responses were returned directly to the research team. This process yielded 713 usable responses, representing a sample-weighted response rate of 69 per cent (60 per cent for the town and 85 per cent for the mental health department).

The dependent variable of interest is a three-item scale that captures rule-following 
attitudes, based on the assumption that attitudes influence behavior (Ajzen \& Fishbein, 2005). In empirical support of this proposition, a meta-analysis of 88 studies found that attitudes significantly and strongly predicted future behavior (Kraus, 1995). Attitude-behavior relationships are strongest when the object of attitudes and behavior are specific and aligned with one another (Ajzen \& Cote, 2008), as in this study. Attitudes have been used as a proxy for rule following behavior in a number of studies (Portillo \& DeHart-Davis, 2009; DeHart-Davis, 2009b).

The survey items used to measure rule-following attitudes are described in Table 3, along with those used to measure the explanatory variables of rule formalization and consistency. These measures of rule-following attitudes were adapted from Baker et al. (1973) and Gordon (1970) and have been used since that time in green tape survey research (DeHart-Davis, 2009a; 2009b). For the first and third items, 0 represents strongly disagree and 4 represents strongly agree; a higher level of agreement indicates more rule following. For the second item that asks about pointless rules, 0 represents strongly agree and 4 represents strongly disagree, indicating that a higher level of disagreement indicates more rule following. Cronbach's alpha for these items is 0.70 . Descriptive statistics provided in Table 4 suggest that organization members largely agree that they obey dislikable rules and assume that rules are there for a purpose, and mostly disagree that they will circumvent rules that they find pointless. For the purpose of analysis, these items were added together to create a summative scale to measure rule-following attitudes. Survey participants on average exhibit favorable rule-following attitudes, as the three rule-following items together have a mean of 9.5 (out of a maximum value of 12). 
Table 3. Survey Items Used to Measure Dependent and Independent Variables

\begin{tabular}{|l|l|l|}
\hline Construct & Survey Measure & Scale \\
\hline $\begin{array}{l}\text { Rule Following (Dependent } \\
\text { Variable) } \\
\text { obey it. (Obey) }\end{array}$ & $\begin{array}{l}\text { 0-Strongly Disagree; 1- } \\
\text { Disagree; 2-Neither Agree nor } \\
\text { Disagree; 3-Agree, 4-Strongly } \\
\text { Agree }\end{array}$ \\
\hline $\begin{array}{l}\text { Rule Following (Dependent } \\
\text { Variable) }\end{array}$ & $\begin{array}{l}\text { If I think a rule is pointless, I will } \\
\text { find } \text { a way around it. (Pointless, } \\
\text { Reversed) }\end{array}$ & $\begin{array}{l}\text { 0-Strongly Disagree; 1- } \\
\text { Disagree; 2-Neither Agree nor } \\
\text { Disagree; 3-Agree, 4-Strongly } \\
\text { Agree }\end{array}$ \\
\hline $\begin{array}{l}\text { Rule Following (Dependent } \\
\text { Variable) }\end{array}$ & $\begin{array}{l}\text { Ifigure rules are there for a } \\
\text { purpose. (Purpose) }\end{array}$ & $\begin{array}{l}\text { 0-Strongly Disagree; 1- } \\
\text { Disagree; 2-Neither Agree nor } \\
\text { Disagree; 3-Agree, 4-Strongly } \\
\text { Agree }\end{array}$ \\
\hline $\begin{array}{l}\text { Rule Formalization } \\
\text { (Independent Variable) }\end{array}$ & $\begin{array}{l}\text { To what extent are rules in your } \\
\text { workplace written? }\end{array}$ & $\begin{array}{l}\text { No or Few Rules- 0, Some } \\
\text { Rules-1, and Many or All Rules- } \\
2\end{array}$ \\
\hline $\begin{array}{l}\text { Rule Consistency (Independent } \\
\text { Variable) }\end{array}$ & $\begin{array}{l}\text { To what extent are rules in your } \\
\text { workplace consistently applied? }\end{array}$ & $\begin{array}{l}\text { No or Few Rules- 0, Some } \\
\text { Rules-1, and Many or All Rules- } \\
2\end{array}$ \\
\hline
\end{tabular}

The independent variables are rule formalization and rule consistency, measured by two separate items that ask for the extent of workplace rules that are written and consistent, respectively (Table 3). Response choices include 'None,' 'Few,' 'Some,' 'Many,' or 'All Rules,' coded as 0 to 4 . The average respondent indicates between some and many rules are written (mean is 2.67), while the average respondent indicates slightly more than some rules are consistent (mean is 2.11). Because few respondents indicated that No or All rules are written and consistent, these categories were collapsed from the original data into three rather than five categories each: 'No' or 'Few' rules are coded as 0, 'Some' is coded as 1, and 'Many' or 'All' rules are coded as 2 . When the responses are collapsed into no/few rules, some rules, and many/all rules (coded as 0 to 2), the average respondent reports between some and many/all rules are written (mean is 1.53) and that on average some rules are consistently applied (mean is 1.06).

Control variables include gender and supervisory status. Gender is included based on theoretical expectations that women are more likely to follow rules more than men due to 
differing cultural expectations for gender behavior (Portillo \& DeHart-Davis 2009). Supervisory status is included based on the expectation that rule behavior depends on hierarchical status and that supervisors will generally have more latitude to bend rules than non-supervisors. Women comprise 49 per cent of the sample and supervisors make up 25 per cent. We have also employed a fixed effect term to account for organizational variation. While the use of the fixed effect completely separates the between organization variation, it accounts for other unobservable organization effects as well.

As shown in Table 4, the items comprising the summative scale to measure the dependent variable of rule following ('obey', 'pointless', and 'purpose' ) are all positively correlated with one another. The independent variables of rule formalization ('written') and rule consistentcy are positively correlated at the .36 level, demonstrating their distinctive attributes as measured in the current study. Finally, rule following attitudes are positively correlated with the independent variables of rule formalization and rule consistency at the .15 and .21 levels, respectively. 
Table 4: Descriptive Statistics of Survey Responses

\begin{tabular}{|c|c|c|c|c|c|c|c|c|c|c|c|c|c|}
\hline Item & $\mathbf{N}$ & Range & Mean & SD & $\begin{array}{c}\text { Rule } \\
\text { Following }\end{array}$ & Obey & Pointless & Purpose & Written & Consistent & Women & Supervisor & City \\
\hline $\begin{array}{l}\text { Rule } \\
\text { Following }\end{array}$ & 624 & $2-12$ & 9.516 & 1.911 & 1.000 & - & - & - & - & - & - & - & - \\
\hline Obey & 624 & $0-4$ & 3.271 & 0.763 & $0.830 * *$ & 1.000 & - & - & - & - & - & - & - \\
\hline Pointless & 624 & $0-4$ & 3.011 & 0.924 & $0.784 * *$ & $0.427 * *$ & 1.000 & - & - & - & - & - & - \\
\hline Purpose & 624 & $0-4$ & 3.220 & 0.723 & $0.778 * *$ & $0.595 * *$ & $0.342 * *$ & 1.000 & - & - & - & - & - \\
\hline Written & 618 & $0-2$ & 1.533 & 0.664 & $0.154 * *$ & $0.084 *$ & $0.131 * *$ & $0.147 * *$ & 1.000 & - & - & - & - \\
\hline Consistent & 617 & $0-2$ & 1.056 & 0.764 & $0.211 * *$ & $0.113 * *$ & $0.159 * *$ & $0.230 * *$ & $0.360 * *$ & 1.000 & - & - & - \\
\hline Women & 620 & $0-1$ & 0.485 & 0.500 & $0.133 * *$ & $0.107 * *$ & $0.132 * *$ & 0.074 & -0.076 & 0.038 & 1.000 & - & - \\
\hline Supervisor & 614 & $0-1$ & 0.248 & 0.432 & -0.006 & 0.056 & $-0.100 *$ & 0.048 & $0.105 * *$ & 0.077 & $0.148 * *$ & 1.000 & - \\
\hline City & 624 & $0-1$ & 0.352 & 0.748 & $0.177 * *$ & $0.136^{* *}$ & $0.189 * *$ & 0.078 & 0.018 & $0.181 * *$ & $.462 * *$ & $-.276^{* *}$ & 1.000 \\
\hline
\end{tabular}

$* \mathrm{p}<0.05 ; * * \mathrm{p}<0.01$ 
An OLS regression model tests the influence of rule formalization and consistency on rule following attitudes. Other modeling strategies like ordered logistic regression could also be used to model the data. However, Winship and Mare (1984) note that ordered logistic models assume an error distribution that is logistically distributed, and violations of this assumption may influence both the biasedness of the parameter as well as tests of significance. OLS models are unbiased even though they may technically violate the Gauss-Markov assumption of noncontinous data, but this only affects the test of significance. Additionally, OLS model are much easier to interpret, especially with the use of interaction terms, and further justify its use (Angrist \& Pischke 2008).

We also test the interaction between rule formalization and consistency to explore its impact on rule following. To reduce multicollinearity between these two variables and their resulting interaction term, rule formalization and consistency were mean-centered first and then multiplied to create the interaction term. Results are reported in Table 5. 
Table 5. Green Tape Attributes and Rule Following

\begin{tabular}{|c|c|c|c|c|}
\hline \multirow[b]{2}{*}{ Variable } & \multicolumn{2}{|c|}{$\begin{array}{c}\text { Model 1 } \\
\mathrm{R}^{2}=0.072 ; \mathrm{F}=10.314 * *\end{array}$} & \multicolumn{2}{|c|}{$\begin{array}{c}\text { Model 2 } \\
\mathrm{R}^{2}=0.089 ; \mathrm{F}=10.848^{* *}\end{array}$} \\
\hline & $\boldsymbol{\beta}$ & $\begin{array}{c}\text { Standardized } \\
\beta\end{array}$ & $\boldsymbol{\beta}$ & $\begin{array}{c}\text { Standardized } \\
\beta\end{array}$ \\
\hline Constant & $\begin{array}{l}8.356 * * \\
(0.21)\end{array}$ & - & $\begin{array}{l}8.048 * * \\
(0.23)\end{array}$ & - \\
\hline Written & $\begin{array}{c}0.327 * * \\
(0.12)\end{array}$ & $0.115 * *$ & $\begin{array}{c}0.513 * * \\
(0.13)\end{array}$ & $0.183^{* *}$ \\
\hline Consistent & $\begin{array}{c}0.364 * * \\
(0.11)\end{array}$ & $0.147 * *$ & $\begin{array}{l}0.300 * * \\
(0.11)\end{array}$ & $0.121 * *$ \\
\hline Women & $\begin{array}{l}0.341^{*} \\
(0.17)\end{array}$ & $0.09 *$ & $\begin{array}{l}0.313 \\
(0.17)\end{array}$ & 0.082 \\
\hline Supervisor & $\begin{array}{l}0.039 \\
(0.18)\end{array}$ & 0.009 & $\begin{array}{l}0.073 \\
(0.18)\end{array}$ & 0.017 \\
\hline City Fixed Effect & $\begin{array}{l}0.415 \\
(0.19)\end{array}$ & $0.102 * *$ & $\begin{array}{l}0.387 \\
(0.19)\end{array}$ & $0.095 *$ \\
\hline $\begin{array}{l}\text { Interaction } \\
\text { (written } \mathrm{x} \\
\text { consistent) }\end{array}$ & - & - & $\begin{array}{c}0.569 * * \\
(0.16)\end{array}$ & $0.152 * *$ \\
\hline
\end{tabular}

$* \mathrm{p}<0.05 ; * * \mathrm{p}<0.01$, standard errors in parentheses

Model 1 in Table 5 supports the first and second hypotheses, that rule following will increase in the presence of rule formalization and rule consistency. Model 2, which interacts rule consistency and rule formalization, confirms the findings in Model 1: rule formalization and consistency correlate with rule following, with the interaction of rule formalization and consistency strengthening the correlation. Gender has a positive relationship with rule following attitudes in model 1, but there is no significant relationship with supervisory status in either model.

To understand the substantive significance of this interaction, the values are plotted in Figure 5. The fit lines indicate three categories of rule formalization, noted in the figure as the 
extent to which rules are written: None or Few (0), Some (1), and Many or All (2). When respondents report that no or few rules are written, there is a negligible weakening in rule following attitudes as consistency increases. When respondents indicate that some rules are written, rule following attitudes slightly weaken as rule consistency increases. By contrast, when respondents indicate that many or all rules are written, rule following attitudes strengthen as consistency increases. This indicates that consistency packs the biggest punch when many or all rules are written, which is in line with our theoretical expectations.

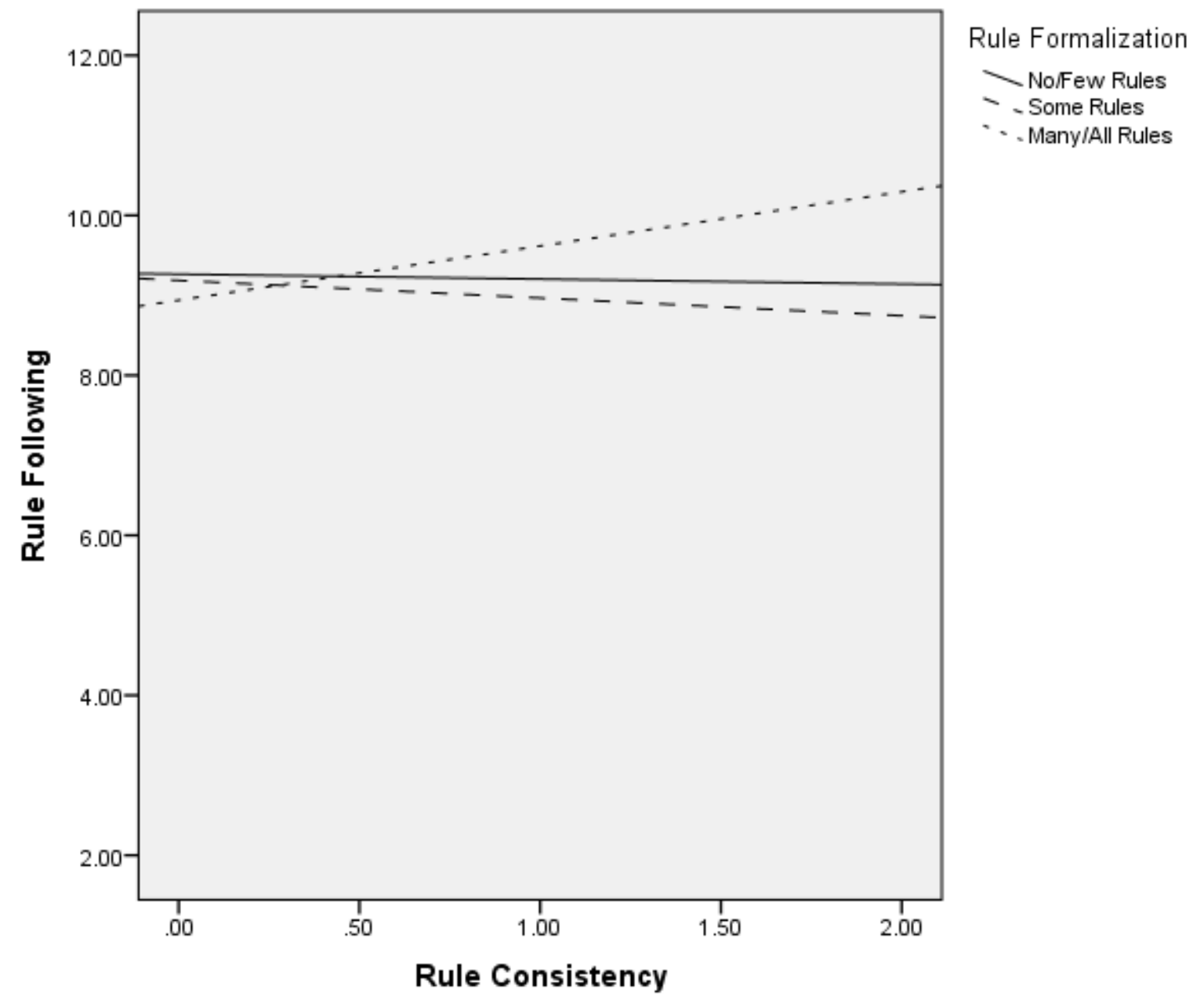

Figure 5.

Rule Consistency, Formalization and Rule Following 
Of note here are the low $\mathrm{R}^{2}$ values in these models. Given the simplicity of these models, testing the impact of only five and six variables on our dependent variable, respectively, this is not surprising. What is somewhat surprising is the relatively large increase once the interaction is introduced: variance explained increases from 7.2 per cent to 8.9 per cent. This increase of close to 2 per cent, while small in absolute terms, represents a 23 per cent increase in overall variance explained.

\section{Discussion}

This research examines the influence of two organizational rule attributes - rule formalization and rule consistency_on organizational rule following in public organizations. Rule formalization, the extent to which rules are available in writing, was hypothesized to increase rule following by infusing rule requirements with greater legitimacy and focusing the attention of organizational members. Rule consistency was also hypothesized to elicit rule following, by conveying peer support for rule requirements. The third hypothesis expected the combination of rule formalization and rule consistency to interact to increase rule following beyond their independent effects.

Across studies, rule formalization is associated with rule following. This finding suggests the power of written rules for achieving organizational preferences, by legitimizing rule requirements and focusing organizational member requirements on them. For government reform advocates who propose internal deregulation as one strategy for increasing the efficiency and responsiveness of public organizations (Osborne \& Gaebler, 1992), the results of this study raise an interesting question: does internal deregulation reduce public sector capacity for achieving 
organizational preferences? The question is particularly poignant if, as some scholars have suggested, internal deregulation simply shifts rules from written to unwritten form (Stokes \& Clegg, 2002; McCullough \& Shannon, 1977). Future research should explore these possibilities.

Also across studies, rule consistency correlates with rule following. That consistency fosters rule following suggests what Brehm and Gates hypothesized (1997): public employees pay close attention to peripheral cues about appropriate behavior. This finding sheds a different light on the public organizational rules literature, which tends to focus on rule rigidity as a worstcase characteristic of organizational rules (March, Schulz \& Zhou, 2000). Rule consistency is not about rule rigidity, but rather is about not systematically exempting specific people or groups from the rules intended to cover them (DeHart-Davis, 2009a). From a theoretical perspective, rule consistency emerges as a fundamental attribute of rule implementation and a rule behavior with implications for rule effectiveness and informal structure.

While all three studies support the first two hypotheses, there is mixed support for the anticipated interaction effect of rule formalization and consistency on rule following. The survey study supports an interaction effect on rule following, measured using rule-following attitudes. But the second study, a vignette experiment, failed to detect an interaction effect. In the survey results, the interaction effect was not uniform: consistency increased favorable attitudes towards rule following only when many or all rules were written. This result makes intuitive sense: written rules provide a standard by which consistent application can be measured. If rules are perceived as less formal — that is, not written — consistency may have less meaning. Future research should continue to investigate individual green tape attributes, but also examine their combined effects on rule behavior. 
Beyond rule attributes, the results of this study pose two implications for practice. First, that written rules achieve more rule following than unwritten rules suggests that formal structure is a powerful determinant of rule behavior. But consistency's effect on rule following suggests that informal social structure within an organization also regulates behavior, echoing North's thesis that informal structures (behavioral codes, conventions, customs) profoundly influence formal mechanisms imposed by government (1990). Informal organizational structure resides outside the personnel manual and organization chart, providing signals to organizational members about acceptable behavior (Chisholm, 1992; Barnard, 1968; Selznick, 1948; Gulati \& Puranam, 2009; Soda \& Zaheer, 2014). Through information about the behavior of like others, rule consistency provides one such signal that triggers imitative rule behavior (Brehm \& Gates, 1997). Organizational rules thus contain elements of both formal and informal structure.

A second implication pertains to the validity of green tape theory, which argues the importance of rule formalization and consistency for eliciting rule following (DeHart-Davis, 2009a). Green tape theory argues that well-designed rules require willing followers (DeHartDavis 2009), which raises questions about whether rule following equates to rule effectiveness. The answer from a green tape theory perspective is no, particularly when rules are poorly designed or used for illegitimate purposes (DeHart-Davis 2017).

\subsection{Limitations}

Despite the insights that this multi-method study provides into the relationship between rule attributes and rule following, it is important to note the study's limitations. First, the experimental vignettes involve a rule that, to some, may seem excessively rigid and illogical. However, this type of a rule is not uncommon in local government organizations (DeHart-Davis, 
2017). What appears as a bad rule from the viewpoint of an academic may seem an effective rule to the managers and MPA students who participated in this study. Such a subjective evaluation is difficult to determine without understanding organizational purposes and workplace context. We do not construe the content of the experimental rule conditions as green tape, but rather seek to isolate the relationships between two green tape attributes and rule following. Thus, we acknowledge that our test of green tape theory is partial and should be extended in future research.

The conduct of research in the U.S., where managerial concerns over liability can drive rule behavior (Epp 1998), raises questions about the generalizability of results. This limitation is rendered less significant by the inclusion of survey data from local government employees located across the hierarchy, many of whom do not face the risks of lawsuits and legal infractions. Nonetheless, comparative research would be a welcome contribution to public administration research on rule behavior.

Another limitation, from the experimental design, is the use of a simple and straightforward rule that focuses on employee punctuality, which represents a clearly defined organizational preference that is easily understood by rule stakeholders and relatively uncontestable as an organizational goal. Furthermore, the 'outcome' of following or bending our fictitious rule is dichotomous: either the employee is suspended, or not. Yet, many organizational rules exist in practice for which purposes, implications, and outcomes are much more ambiguous. As the literature on regulatory compliance conveys, ambiguity can pose a barrier to rule following and clear rules are generally easier to follow (Gilad 2014; Weaver, 2014; 2015). While this study used an unambiguous rule to isolate the effect of rule formalization and consistency on compliance, future studies should incorporate ambiguity as a covarying rule 
attribute to reflect a broader range of real-world conditions.

We acknowledge that the rule used in our experimental studies is stylized and that organizational reality is much more complex. At the same time, limiting external validity in favor of being able to test for causality is worthwhile in this case because we see the individual effects of written and consistent rules. This limitation is partially mitigated by the research design, which involves a survey study to increase contextual realism and external validity. Another qualification pertains to the experiment's omission of consequences for rule violations. While consequences for rule violation can influence rule behavior, the influence is limited when rule violations carry little consequence. This tendency toward rule nonconsequence has been observed in a wide array of organizational settings, from narcotics law enforcement (Manning, 1977) to safety rules (Reason, Parker, \& Lawton, 1998) to minority contracting (Terman, 2017). Given that rules are mostly followed in public organizations, detecting and punishing rule volations becomes an ineffective investment of managerial time. Future research should consider the impact of rule violation consequences when studying rule behavior by employees.

Construct validity of our experimental measures is also an issue. Most notably, written and unwritten rules were both conveyed to research subjects in writing, triggering the question of whether unwritten rules could have been more validly communicated in the experiment through auditory means, such as, audio or visual media. While this is a legitimate research consideration that should be addressed in future research, the current research design likely underestimates the compliance differential in written and unwritten rules by infusing the unwritten rule with the authority of the written word (DeHart-Davis et al., 2013). 
A final comment pertains to the study's measures of rule following. The experiment measured rule following as a research participant's stated decision to follow or break a rule. The survey's compliance measure was multi-dimensional, tapping compliance attitudes towards rule following. Employing both attitudes and stated intentions as dependent variabes allowed us to measure both the 'talk' and the 'walk' of rule compliance. Because attitudes preceed intention (Ajzen \& Fishbein, 2005), the use of both constructs allowed us to tap multiple locations on the rule behavior spectrum (DeHart-Davis, 2017). Furthermore, there is evidence that intentions correlate with actual behavior when the context of the vignette is similar to a real-life context that the respondent is likely to face (Aguinis, 2014). This holds particularly true for our second experiment, in which public managers were asked to respond to a situation that they are likely to encounter in their everyday activities. Yet, it is important to acknowledge that the responses in the experiment and survey are attitudes and intended actions, which may vary in different contexts. Again, longitudinal case studies that combine observational and archival data can offer important insights into these topics.

\section{Conclusion}

This examination of organizational rule attributes and rule following marks a new direction in public management and organizational research, which has tended to focus on rules as a monolithic form of structure (Pugh, et al., 1968). Our focus on rule attributes not only enhances understanding of effective organizational rules (albeit incompletely so), it also offers

practical implications that can be acted upon by public managers in the pursuit of organizational effectiveness. Given the instrumental role of organizational rules in public sector functioningwhether to symbolize public values, ensure efficient and effective operations, or signal 
organizational legitimacy_rule behavior research merits a permanent spot on public administration research agendas. 


\section{REFERENCES}

Adler, P. S., \& Borys, B. (1996). Two types of bureaucracy: Enabling and coercive. Administrative Science Quarterly, 41(1), 61-89.

Aguinis, H., \& Bradley, K. J. (2014). Best practice recommendations for designing and implementing experimental vignette methodology studies. Organizational Research Methods, 17(4), 351-371.

Ajzen, I., \& Cote, N. G. (2008). Attitudes and the prediction of behavior. In W. D. Crano \& R. Prislin (Eds.), Attitudes and attitude change (pp. 289-311). New York: Psychology Press.

Ajzen, I., \& Fishbein, M. (2005). The influence of attitudes on behavior. The handbook of attitudes, 173, 221.

Angrist, J. D., \& Pischke, J.-S. (2008). Mostly harmless econometrics: An empiricist's companion. Princeton, NJ: Princeton University Press.

Baker, S. H., Etzioni, A., Hansen, R. A., \& Sontag, M. (1973). Tolerance for bureaucratic structure: Theory and measurement. Human Relations, 26(6), 775-786.

Barnard, C. I. (1968). The functions of the executive (Vol. 11): Harvard university press.

Battmann, W., \& Klumb, P. (1993). Behavioural economics and compliance with safety regulations. Safety Science, 16(1), 35-46.

Bertelli, A. M., \& Whitford, A. B. (2009). Perceiving credible commitments: How independent regulators shape elite perceptions of regulatory quality. British Journal of Political Science, 39(3), 517-537.

Blader, S. L., \& Tyler, T. R. (2003). A four-component model of procedural justice: Defining the meaning of a 'fair' process. Personality and Social Psychology Bulletin, 29(6), 747-758.

Borry, E. L. (2017). Ethical climate and rule bending: How organizational norms contribute to unintended rule consequences. Public Administration, 95(1), 78-96. doi:10.1111/padm.12304

Bozeman, B. (2000). Bureaucracy and red tape. Upper Saddle River, NJ: Prentice Hall.

Bozeman, B., \& Rainey, H. G. (1998). Organizational Rules and the 'Bureaucratic Personality'. American Journal of Political Science, 42(1), 163-189. doi:10.2307/2991751

Brehm, J., \& Gates, S. (1997). Working, Shirking, and Sabotage: Bureaucratic Response to a Democratic Republic. Ann Arbor, MI: Michigan University Press.

Campbell, D. T. (1963). Experimental and quasi-experimental designs for research. Chicago, IL: Rand McNally.

Cialdini, R. B. (1984). Influence: The new psychology of modern persuasion. New York: Quill.

DeHart-Davis, L. (2007). The unbureaucratic personality. Public Administration Review, 67(5), 892-903.

DeHart-Davis, L. (2009a). Green tape: A theory of effective organizational rules. Journal of Public Administration Research and Theory, 19(2), 361-384.

DeHart-Davis, L. (2009b). Green tape and public employee rule abidance: Why organizational rule attributes matter. Public Administration Review, 69(5), 901-910.

DeHart-Davis, L. (2017). Creating Effective Rules in Public Organizations. Washington, DC: Georgetown University Press.

DeHart-Davis, L., Chen, J., \& Little, T. (2013). Written versus unwritten rules: The role of rule formalization in green tape. International Public Management Journal, 16(3), 331-356. 
DeHart-Davis, L., Davis, R. S., \& Mohr, Z. (2014). Green Tape and Job Satisfaction: Can Organizational Rules Make Employees Happy? Journal of Public Administration Research and Theory, 25(3), 849-876.

Dillman, D. A., Smyth, J. D., \& Christian, L. M. (2009). Internet, mail, and mixed-mode surveys: The tailored design method. Hoboken, NJ: Wiley.

Epp, C. R. (1998). The rights revolution: Lawyers, activists, and supreme courts in comparative perspective: University of Chicago Press.

Festinger, L. (1954). A theory of social comparison processes. Human Relations, 7(2), 117-140.

Gilad, Sharon. (2014). Beyond Endogeneity: How Firms and Regulators Co-Construct the Meaning of Regulation. Law Policy 36 (2): 134-64.

Gordon, L. V. (1970). Measurement of bureaucratic orientation. Personnel Psychology, 23(1), 111.

Gulati, R., \& Puranam, P. (2009). Renewal through reorganization: The value of inconsistencies between formal and informal organization. Organization Science, 20(2), 422-440.

Hasselbladh, H., \& Kallinikos, J. (2000). The project of rationalization: a critique and reappraisal of neo-institutionalism in organization studies. Organization Studies, 21(4), 697-720.

Henderson, A. C. (2013). Examining policy implementation in health care: Rule abidance and deviation in emergency medical services. Public Administration Review, 73(6), 799-809.

Hutchinson, S. A. (1990). Responsible subversion: A study of rule-bending among nurses. Scholarly Inquiry for Nursing Practice, 4(1), 3-17.

Kallinikos, J. (1996). Predictable worlds: on writing, accountability and other things. Scandinavian Journal of Management, 12(1), 7-24.

Kaufman, H. (1960). The Forest Ranger: A Study in Administrative Behavior. Washington, DC: Resources for the Future.

Kaufmann, W., \& Feeney, M. K. (2012). Objective Formalization, Perceived Formalization and Perceived Red Tape. Public Management Review, 14(8), 1195-1214.

Kaufmann, W., \& Feeney, M. K. (2014). Beyond the rules: The effect of outcome favourability on red tape perceptions. Public Administration, 92(1), 178-191.

Kieser, A., Beck, N., \& Tainio, R. (2001). Rules and organizational learning. In M. Dierkes, A. B. Antal, J. Child, \& I. Nonaka (Eds.), Handbook of Organizational Learning and Knowledge (pp. 598-623). Oxford: Oxford University Press.

Kraus, S. J. (1995). Attitudes and the prediction of behavior: A meta-analysis of the empirical literature. Personality and Social Psychology Bulletin, 21(1), 58-75.

Kydland, F. E., \& Prescott, E. C. (1977). Rules rather than discretion: The inconsistency of optimal plans. Journal of political economy, 85(3), 473-491.

Leventhal, G. S. (1980). What should be done with equity theory? In K. J. Gergen, M. S. Greenberg, \& R. H. Willis (Eds.), Social Exchange: Advances in Theory and Research (pp. 27-55). New York: Springer.

Levi, M., Sacks, A., \& Tyler, T. (2009). Conceptualizing legitimacy, measuring legitimating beliefs. American Behavioral Scientist, 53(3), 354-375.

Levitt, B., \& March, J. G. (1988). Organizational learning. Annual Review of Sociology, 14(1), 319-338.

Lipsky, M. (1980). Street-Level Bureaucracy: Dilemmas of the Individual in Public Services. New York: Russell Sage.

Manning, P. K. (1977). Rules in Organizational Context: Narcotics Law Enforcement in Two Settings. The Sociological Quarterly, 18(1), 44-61. 
March, J. G., Schulz, M., \& Zhou, X. (2000). The Dynamics of Rules: Change in Written Organizational Code. Stanford: Stanford University Press.

March, J. G., \& Simon, H. A. (1958). Organizations. Oxford: Wiley.

Maynard-Moody, S., \& Musheno, M. (2003). Cops, Teachers, Counselors: Stories from the Front Lines of Public Service. Ann Arbor: University of Michigan Press.

Maynard-Moody, S., \& Portillo, S. (2010). Street-Level Bureaucracy Theory. In R. Durant (Ed.), Handbook of American Bureaucracy. New York: Oxford University Press.

McCullough, A., \& Shannon, M. (1977). Organizations and protection. Critical issues in organizations, 72-85.

McPhee, R. D. (2004). Text, agency, and organization in the light of structuration theory. Organization, 11(3), 355-371.

Merton, R. K. (1940). Bureaucratic Structure and Personality. Social Forces, 18(4), 560-568.

Morrison, E. W. (2006). Doing the Job Well: An Investigation of Pro-Social Rule Breaking. Journal of Management, 32(1), 5-28.

Moynihan, D. P. (2013). Does public service motivation lead to budget maximization? Evidence from an experiment. International Public Management Journal, 16(2), 179-196.

North, D. C. (1990). Institutions, institutional change and economic performance: Cambridge university press.

Ocasio, W. (1997). Towards an attention-based view of the firm. Strategic Management Journal, 187-206.

Olsen, J. P. (2006). Maybe it is time to rediscover bureaucracy. Journal of Public Administration Research and Theory, 16(1), 1-24.

Osborne, D., \& Gaebler, T. (1992). Reinventing government: How the entrepreneurial spirit is transforming the public sector. Reading, MA: Addison-Wesley.

Pandey, S. K., \& Moynihan, D. P. (2006). Bureaucratic red tape and organizational performance: Testing the moderating role of culture and political support. In G. Boyne, K. J. Meier, L. J. O'Toole Jr, \& R. M. Walker (Eds.), Public Service Performance. Cambridge, England: Cambridge University Press.

Perry, J. L. (2012). How can we improve our science to generate more usable knowledge for public professionals? Public Administration Review, 72(4), 479-482.

Portillo, S., \& DeHart-Davis, L. (2009). Gender and Organizational Rule Abidance. Public Administration Review, 69(2), 339-347.

Pugh, D. S., Hickson, D. J., Hinings, C. R., \& Turner, C. (1968). Dimensions of organization structure. Administrative Science Quarterly, 13(1), 65-105.

Reason, J., Parker, D., \& Lawton, R. (1998). Organizational controls and safety: The varieties of rule-related behaviour. Journal of Occupational and Organizational Psychology, 71(4), 289-304. doi:10.1111/j.2044-8325.1998.tb00678.x

Riccucci, N. (2005). How management matters: Street-level bureaucrats and welfare reform: Georgetown University Press.

Romzek, B. S., \& Dubnick, M. J. (1987). Accountability in the Public Sector: Lessons from the Challenger Tragedy. Public Administration Review, 47(3), 227-238.

Roth, W. D., \& Sonnert, G. (2011). The costs and benefits of 'red tape': Anti-bureaucratic structure and gender inequity in a science research organization. Social Studies of Science, 41(3), 385-409. 
Rubin, E. V. (2009). The role of procedural justice in public personnel management: Empirical results from the Department of Defense. Journal of Public Administration Research and Theory, 19(1), 125-143.

Salancik, G. R., \& Pfeffer, J. (1978). A social information processing approach to job attitudes and task design. Administrative Science Quarterly, 224-253.

Sandfort, J. R. (2000). Moving Beyond Discretion and Outcomes: Examining Public Management from the Front Lines of the Welfare State. Journal of Public Administration Research and Theory, 10(4), 729-756.

Scandura, T. A., \& Williams, E. A. (2000). Research methodology in management: Current practices, trends, and implications for future research. Academy of Management Journal, 43(6), 1248-1264.

Schulz, M. (2003). Impermanent institutionalization: The duration dependence of organizational rule changes. Industrial and Corporate Change, 12(5), 1077-1098.

Sekerka, L. E., \& Zolin, R. (2007). Rule-Bending: Can Prudential Judgment Affect Rule Compliance and Values in the Workplace? Public Integrity, 9(3), 225-243.

Selznick, P. (1948). Foundations of the theory of organization. American Sociological Review, 13(1), 25-35.

Sitkin, S. B., \& Bies, R. J. (1993). The legalistic organization: Definitions, dimensions, and dilemmas. Organization Science, 4(3), 345-351.

Soda, G., \& Zaheer, A. (2012). A network perspective on organizational architecture: performance effects of the interplay of formal and informal organization. Strategic Management Journal, 33(6), 751-771.

Stinchcombe, A. L. (2000). Social structure and organizations. In J. A. C. Baum \& F. Dobbin (Eds.), Economics Meets Sociology in Strategic Management (pp. 229-259): Emerald Group Publishing Limited.

Stokes, J., \& Clegg, S. (2002). Once upon a time in the bureaucracy: power and public sector management. Organization, 9(2), 225-247.

Sutcliffe, K. M., \& McNamara, G. (2001). Controlling decision-making practice in organizations. Organization Science, 12(4), 484-501.

Terman, J. N. (2017). What Happens When Rules Stay the Same? Examining Changes in Implementation Intent over Time. International Journal of Public Administration, 40(1), $36-53$.

Tummers, L. (2011). Explaining the willingness of public professionals to implement new policies: a policy alienation framework. International Review of Administrative Sciences, 77(3), 555-581. doi:doi:10.1177/0020852311407364

Tummers, L. (2012). Policy alienation of public professionals: The construct and its measurement. Public Administration Review, 72(4), 516-525.

Tummers, Lars, Ulrike Weske, Robin Bouwman, and Stephan Grimmelikhuijsen. 2016. The Impact of Red Tape on Citizen Satisfaction: An Experimental Study. International Public Management Journal 19 (3): 320-41.

Tyler, T. R. (2006). Psychological perspectives on legitimacy and legitimation. Annual Review of Psychology, 57(1), 375-400. doi:doi:10.1146/annurev.psych.57.102904.190038

Tyler, T. R., \& Blader, S. L. (2001). Identity and cooperative behavior in groups. Group Processes \& Intergroup Relations, 4(3), 207-226. 
Tyler, T. R., \& Blader, S. L. (2005). Can Businesses Effectively Regulate Employee Conduct? The Antecedents of Rule following in Work Settings. The Academy of Management Journal, 48(6), 1143-1158.

Tyler, T. R., \& Lind, E. A. (1992). A relational model of authority in groups. Advances in experimental social psychology, 25, 115-191.

Van den Bos, K., Lind, E. A., Vermunt, R., \& Wilke, H. A. (1997). How do I judge my outcome when I do not know the outcome of others? The psychology of the fair process effect. Journal of Personality and Social Psychology, 72(5), 1034.

Vlaar, P. W., Van den Bosch, F. A., \& Volberda, H. W. (2006). Coping with problems of understanding in interorganizational relationships: Using formalization as a means to make sense. Organization Studies, 27(11), 1617-1638.

Weaver, R. K. (2014). Compliance regimes and barriers to behavioral change. Governance, 27(2), 243-265.

Weaver, R. K. (2015). Getting people to behave: Research lessons for policy makers. Public Administration Review, 75(6), 806-816.

Weber, M. (1946). From Max Weber: essays in sociology (C. W. Mills \& H. H. Gerth, Trans.). New York: Oxford University Press.

Weber, M. (1947). The Theory of Social and Economic Organization (A. M. Henderson \& T. Parsons, Trans.). Glencoe: Free Press.

Winship, C., \& Mare, R. D. (1984). Regression models with ordinal variables. American Sociological Review, 512-525.

Wise, L. R. (2004). Bureaucratic Posture: On the Need for a Composite Theory of Bureaucratic Behavior. Public Administration Review, 64(6), 669-680. doi:10.1111/j.15406210.2004.00414.x 